\title{
Bilingualism: language policy in modern Kazakhstan
}

\author{
Tulebike Kulgildinova - Aigul Zhumabekova - Kuralay Shabdenova - Laila \\ Kuleimenova - Perizat Yelubayeva
}

DOI: 10.18355/XL.2018.11.01.28

\begin{abstract}
The creation of a fair language policy acts as one of the main tasks in multiethnic society. Sociopolitical realities of Kazakhstan as sovereign state demand new language policy that would have to meet needs of the multiethnic population of the country and consider features of a language, demographic and political situation. Today in Kazakhstan works the Concept of language policy directed to expansion of the functioning sphere of a state language and defines Russian as the main source of information and as the mode of communication. The existing model of languages functional development defined in the Concept also assumes the creation of an optimum language space of the state, in this connection, an accurate definition of a functional ratio of languages, at which the state language had to take the worthy place, is required. The goal gives to Kazakh language function of international communication language, demands adoption of the new legislation and accurate state programs of functioning and development of languages. According to the Concept, interests of the economic, scientific, and technical development of the country define demand for knowledge and education received in Russian. Preservation of the functioning sphere of Russian is provided with the aspiration of Kazakhstan to integration processes, preservation of uniform cultural and educational space with the CIS countries.
\end{abstract}

Key words: bilingualism, the state language, minority language, language situation, the Republic of Kazakhstan

\section{Introduction}

The creation of a fair language policy acts as one of the main tasks in multiethnic society (Appel, Muysken, 2005). The feature of modern language policy is, on the one hand, the aspiration to keep ethnic language and culture, with another - the necessity of development of the world for adaptation to new realities of modern society. The question is about the necessity of further improvement of younger generation language education in consideration of the integration processes happening in the Republic of Kazakhstan and the world.

By the standard definition teaching of the native language pursues the creation of conditions for the child to master the first (native) language, which subsequently acts as the dominating mean of communication. Incidentally, crucial importance has the legal, socio-economic and cultural status of the native language. When the native language coincides with national language of the state, i. e. performs all social functions (it is used in the administrative sphere, media, education, and culture), then there are all conditions for the teaching of the native language. In these conditions, cultural and communicative motivations of the child's family coincide with motivations of the national community. When the language situation develops differently, and the child's native language the has only the status of local or regional spread, then relationship of native and national language can be problematic (Adamson, Feng, 2014, pp. 29-44). The language of independent ethnos is taught as native and holds a dominant position in education while national language takes the place of the second language in the curriculum.

If we consider a language situation in the European countries, then we will see that it becomes complicated due to a language variety. In the modern world in the epoch of 
globalization, it is quite difficult to define the dominating language in an educational context. The important factor influencing the choice of language is the legal status of a minority language in this country. In case if minority language has the clear legal status at the national or regional level, then the main problem will be to move this status in a row of socio-economic and cultural behavioral models of the associates wishing to be identified according to the values presented by minority language (Hoffmann, 1991).

Due to the lack of standardization, maintenance of minority languages becomes complicated that leads to inevitable language changes even in spite of any decisionmaking in education (Mehisto, Genesee, 2015). In times in society, there can be a certain socioeconomic and demographic imbalance that can lead to 'memorization' of one or several national and/or official languages. The conflict, which can arise between the minority language community and the majority and prepotent language community, is defined by three major factors: the legal status of the language involved in the conflict, geographical allocation of native speakers within the country, communicative functions.

Reasoning from the listed facts it is supposed that the international language policy has to protect the rights of languages irrespective of native speakers' number and estimate them as a part of the cultural heritage that requires protection. Within modern European language policy, most of the researchers offer training programs in three languages: national language of the country; the local language which gained distribution at the local level; the international foreign language (Marschark, Knoors,

Tang, 2014). The international policy in the languages sphere requires multilateral agreements on exchange of teachers, training programs.

The proper language policy and the elaborated measures for the arrangement of language life can promote peaceful co-existence of the people in the multiethnic country, preservation and development of national cultures and languages, linguistic and cultural diversity in the world. This problem is especially urgent in the modern multipolar world in conditions of the deep social changes connected with the adoption of language statutes, the concept of languages development for the revival of language traditions and expansion of languages social functions of the title peoples in the epoch of globalization, communication and information technologies.

Active processes interethnic and, respectively, cross-cultural and interlingual interaction characterize the modern language situation in the Republic of Kazakhstan. Considering the broad definition of language policy as practical measures of the state, concerning the status of a state language, its functions, protection of exclusive use of a state language in the most important social spheres, a regulation of 'local' languages use (García, Wei, 2015, pp. 223-240), then it is necessary to inquire into bilingualism as in aspect of formation and development of basic competencies, and functionally itself in relation to different types of speech activity and different fields of communication.

The Aim of the Research is an examination of the concept 'bilingualism', analysis the main theories and aspects of bilingualism, the study of a language situation of bilingualism in the Republic of Kazakhstan, based on the existing language policy.

\section{Views on various aspects of bilingualism}

Research interest in bilingualism arose at the end of the 19th century, was related to the development of linguistics and allied sciences (Hoffmann, 1991; Appel, Muysken, 2005). The linguistic aspect of bilingualism is related to the analysis of a ratio of structures and structural elements of two languages, their interferences, interaction and interpenetration at the different levels. Y. Desheriyev and I. Protchenko note that the research of an interference demonstration peculiarity is most important for this

XLinguae, Volume 11, Issue 1, January 2018, ISSN 1337-8384, eISSN 2453-711X 
aspect in the course of both languages use (Desheriyev, Protchenko, 1972, pp. 2642).

Extraordinary versa, the utility of bilingualism as science object generated a set the linguistic theories. Each of them developed based on the solution of those tasks, which were set by researchers when studying one or another aspect of bilingualism linguistic, psychological, sociological, pedagogical, artistic-literary.

From the linguistic point of view, according to U. Vaynraykh, the problem of bilingualism lies in description of those several language systems which complicate simultaneous possession of them, and, thus, predict the most probable interference demonstrations which results from languages contact and, at last, specify in behavior of bilingual speakers those aberrations of each of languages which are connected to their bilingualism (Vaynraykh, 1979). A. Shayakhmetova believes that the linguistic aspect of bilingualism deals with the analysis of a ratio of structures and structural elements of two languages, their interferences, interaction and interpenetration at different levels, sections of a language system: phonologic, morphological, syntactic, lexical-semantic and stylistic (Shayakhmetova, 2002, pp. 6-10). Scientists note that the research of an interference demonstration peculiarity is most important for this aspect in the course of both languages use.

If the linguistic aspect of bilingualism is generally connected with the effect of the linguistic phenomena generated by language contact, then psychological aspect reflects, according to scientists, specifics of speech psychophysiological mechanisms of the person who uses two language systems in communication. The research of psychological aspect of bilingualism helps to give the correlative characteristic of linguistic categories, the concepts 'postponed' in language consciousness of bilingual speakers; memorization peculiarity, perception, comprehension, acoustical (in the speech) and visual (on the letter) perceptions by bilingual collective or individual of the signs, features, categories and concepts specific to the second language and absent in their language consciousness as the first language native speakers. The considerable attention in the psycholinguistic aspect of bilingualism is paid to studying of bilingualism impact on the individual thinking. It is known that from the point of view of relationship of language and thinking L.Shcherba allocated two types of language systems coexistence in consciousness of the person in a bilingual situation - independent connection at a pure bilingualism when the contacting languages form two separate systems of associations in consciousness of the individual and dependent connection at the mixed bilingualism type when the contacting languages form only one system of associations (Shcherba, 1958).

According to N. Lyubimova, the psychological typology of bilingualism is formed in consideration of four criteria:

1) Types of speech activity;

2) Correlation among themselves the speech mechanisms providing knowledge of different languages;

3) A way of connection of the speech in each language with thinking;

4) The way of language proficiency (Lyubimova, 1991).

The psychological aspect of bilingualism includes studying, both speech production mechanisms, and speech perception. For example, there are experimental data that at a bilingual person has a uniform system of perception and two separate speech production systems in native and non-native languages.

The psychological aspect of bilingualism has an extensive perspective in modern researches: foreign-language abilities as psychological prerequisite of bilingualism formation; connection of psycholinguistic problems of a bilingualism with a technique of non-native language teaching; motivational conditions of bilingualism formation (Suleymenova, 2011); interference of speech development in native and foreign languages (Baziyev, Isaev, 1973), etc. 
The sociological aspect of bilingualism studying consists in defining the public functions and scopes of each of two languages that the bilingual population uses (Kurmanova, 2002).

Social researches of bilingualism are intended to define:

1) Allocation of bilingualism among various social, professional groups of multinational labor collectives;

2) Use of bilingualism in the main spheres of public life (production, spiritual, family, and everyday life);

3) Impact on bilingualism of extralinguistic factors: class, ethnic, demographic, etc.;

4) Channels of bilingualism formation;

5) A ratio of national language and language of international communication in the course of bilingualism, etc. (Rakisheva, 2003).

Clarification of social factors role in the development of a mass or group bilingualism, the influence of a scientific and technical revolution on the development of public functions of languages in the conditions of bilingualism also refer to problems of sociolinguistic studying of bilingualism. A sociolinguistic approach to bilingualism found its reflection in the concept of the scientists considering bilingualism as the coexistence of two languages within the same speaking collective using these languages in the respective communicative spheres depending on a social situation and other parameters of the communicative act.

The pedagogical aspect is based on linguistic, psychological and sociolinguistic aspects. Its task consists of development and application of methods of teaching two languages, methods of studying of language acquisition, possession of two languages in the conditions of bilingualism. The didactic aspect of bilingualism is developed on the basis of natural processes of the second language acquisition (Altynbekova, 2003). The pedagogical aspect of bilingualism includes as questions of passive (reading and hearing), and active knowledge of the language (speaking and writing).

The artistic-literary (literary) aspect of bilingualism is connected with studying of speech characteristics of characters in works of art, with the analysis of the fiction created by writers - bilinguals and perceived by bilingual societies.

Each of bilingualism aspects as M. Mikhaylov fairly believes, sometimes acts as the interdisciplinary problem demanding efforts of a number of allied sciences as the linguistic aspect inevitably intertwines in it with psychological, and psychological with pedagogical, artistic-literary with linguistic (Mikhaylov, 1988).

Interest in various aspects of bilingualism and other types of multilingualism does not weaken in connection with a significant role of language policy in modern society. In a practical manner, there is no country in the world where would be no various questions of a language situation, language contacts.

As a material for the analysis served data of censuses, materials of the Agency of the statistics of the Republic of Kazakhstan, the data of mass questioning of 2005 received during the implementation of the INTAS project No. 04-79-7292 'New language identity in transforming societies served: Kazakhstan, Kyrgyzstan, Tajikistan and Uzbekistan', and results of questioning of 2009 executed on the project of Committee on languages of the Ministry of Culture and information of the Republic of Kazakhstan 'The Ethnolinguistic situation in the Republic of Kazakhstan: present and future.

\section{Representation of the development of bilingualism in Kazakhstan}

The description of a language situation of Kazakhstan during the different periods of its development is submitted in works of Suleymenova (2011), Altynbekova (2003).

As the republic's sovereignty was recognized, Kazakh language was given the status of the state language, to Russian - the status of the language of the international communication. In new Post-Soviet conditions a question of languages nationalization

XLinguae, Volume 11, Issue 1, January 2018, ISSN 1337-8384, eISSN 2453-711X 
when the law interferes in national-language relations, it is important to raise the steppe, without humiliating the mountain (Zhanalina, 1998). Otherwise, negative processes in national-language life are inevitable.

Acceptance of language of the title nation in the national republics as state language caused necessity of studying it by representatives of all peoples living in the territory of this republic that promoted the formation of a new type of bilingualism. As the ground for emergence and functioning of bilingualism served transition of Kazakhs to settled life, multinational structure of the northern areas of Kazakhstan, proximity of borders with Russia, territorial contact of one people with another or joint resettlement of the different peoples in one territory, demographic factor: resettlement and migration of peoples to Kazakhstan (Rakhimzhanov, 2005).

According to K. Rakhimzhanov formation of the Kazakh-Russian bilingualism was promoted by the demographic factor: resettlement and migration of peoples to Kazakhstan (Rakhimzhanov, 2005). As the academician B. Kurmanova notes, since the end of the 30th Kazakhstan began to turn into 'Stalin prison of peoples' (Kurmanova, 2002). This conclusion is drawn on the basis of the fact that there was a large number of special immigrants in the Republic (every fifth resident of Kazakhstan was a special immigrant) (Zhanalina, 1998).

B. Khasanov in work 'Languages of International Communication' published 1976, gives full characteristic of the language situation in Kazakhstan. Interaction of languages of peoples of Kazakhstan and also level of language possession of consumers, spheres of use and the main functions in society with concrete statistical data are analyzed in work (Khasanov, Desheriyev, 1976).

In 1982-1984 were published works of M. Kopylenko and S. Saina 'Functioning of Russian language in various layers of Kazakh language', 'A phonetic interference in the Russian speech of Kazakhs' (Kopylenko, Saina, 1982), and in 1987 was issued the second part of this work under the name 'Lexical and Morphological Interference in the Russian Speech of Kazakhs'. In works were considered phonetic, lexical and morphological mistakes made in the speech of Kazakhs when using Russian. The interference phenomena from the sociolinguistic point of view were considered in the following directions:

- Comparative analysis of Kazakh-Russians interference phenomenon;

- Definition of potential interferences area;

- Forwarding observation of informants;

- The analysis and the description of concrete interferences from the linguistic point of view;

- The analysis and the description of interferences phenomenon by questioning and testing;

- A sociolinguistic analysis of the interferences phenomenon.

In 1987-1989 were published scientific works of B. Khasanov (1989). Also in this work were explored experience and levels of proficiency in languages of all ethnic groups living in Kazakhstan in consideration of concrete statistical data. For the first time were given definitions of concepts of a monolingualism, bilingualism, three, four and polylingualism and also provided sociolinguistic descriptions. Two, three and four lingual representatives of ethnic groups meeting on the Kazakhstan experience are described on concrete examples.

In the 1990s in the Kazakhstan sociolinguistics are widely discussed questions of a two-multilingualism and a diglossia and appeared a number of scientific works. For example, in A. Karlinsky work 'Theory bases interaction of languages' (Karlinsky, 1990) are analyzed questions of languages interaction, the emergence of bilingualism, its place in society, natural and artificial bilingualism, were given definitions of concepts language collective, an interference and its types, a typology of intercalations. 
In 1990 was published the collection 'Language Policy in Kazakhstan and a Way of Its Realization' devoted to questions of language policy of Kazakhstan (Language policy in Kazakhstan and a way of her realization, 1990).

In 1992 in B. Xasanul1 'Anatili heritage' (Xasanul1 1992) category of the native language was for the first time studied from the point of view of sociolinguistics. The author gives linguistic, sociolinguistic, psychological, pedagogical, historical and ethnic characteristics of the native language and also defines differences and similarities between concepts the native language and the law, the native language and economy, assimilation and knowledge of the native language, analyzes the language situation of bilingualism, social and communicative system of the country component languages and their functional load, a typology, questions of the state language, requirement of knowledge of Kazakh, need of studying Kazakh within world development of languages. In the monograph B. Khasanov defines the native language as the language isolated by an internal system from all existing languages, it is the language which is historically living with certain people in a certain space and continuously transmitting culture of these people from generations to generations, it is a mean of communications functioning within one nation equally to all men of these people (regardless of age, sex, religion, the social status). The author, during the analysis of bilingualism nature, gives the following definition: The bilingualism is variable or parallel use of two languages (usually native language and the second language) by representatives of the certain ethnic group entering the international (interethnic) relations in an area of certain territories of all community (society) in different situations. B. Khasanov, as follows, describes the Kazakh-Russian bilingualism as typical for this country: "The Kazakh-Russian bilingualism is variable or parallel use by Kazakhs of native and Russian languages inside and international communication in multinational society, use of two languages in different situations as necessary" (Xasanul1, 1992).

B. Khasanov in work during the analysis of spheres of the use, development, and functioning of Kazakh as the state language, marks out the following principles of a state language development:

- The first principle - use of the state language in all organizations, the enterprises and institutions for office and business communication and creation of all conditions for the solution of the matter;

- The second principle - use of the state language in all organizations, the enterprises and institutions in office-work and workflow and creation of all conditions for the solution of the matter;

- The third principle -solution of all financial questions concerning development of the state language;

- The fourth principle - full personnel and educational methodological support for teaching the state language;

- The fifth principle - creation of a state language promotion system in Russian and other languages;

- The sixth principle - the introduction of the annual progress report on the implementation of provisions of the Law on languages to higher bodies and the public.

So far in polylingual Kazakhstan as Z. Akhmetzhanova marks out, was created the set of bi-and polylingualism types which differ in regions of allocation, coverage of different spheres of the functioning of languages, specifics of the influence of the first language on the second, etc. (Akhmetzhanova, 2005). B. Khasanov allocates 126 types of bilingualism consisting of 125 national and Russian languages, about two dozens of Russian-national and national-Kazakh bilingualism, not less than ten types of the national-national bilingualism, and also a trilingualism 
presented by Trinity of the Kazakh, Russian and national components (Xasanul1, 1992).

E. Suleymenova considers the Russian language in Kazakhstan as the major component, on the one hand, Kazakh-Russian, Uigur-Russian, German-Russian and so forth bilingualism, from another, - Russian-Kazakh, Russian-Uigur, RussianGerman and so forth bilingualism (Suleymenova, 2011). Types and the nature of mass bilingualism, a ratio of the Kazakh-Russian and Russian-Kazakh bilingualism are of great interest as well. The scientist speaks about distinctly arising a tendency to the formation at the youth of an equal share of the Kazakh-Russian and Russian-Kazakh bilingualism: $69,7 \%$ of respondents Russians are bilinguals with the second Kazakh and $72,6 \%$ of Kazakh respondents - bilinguals with the second Russian.

In the Aktyubinsk region according to O. Altynbekova researches (Altynbekova, 2003), developed the Kazakh-Russian and national-Russian bilingualism, to a lesser extent - the national-Kazakh bilingualism. On the whole, in the Aktyubinsk region, $67,9 \%$ of Kazakhs knew Russian, including city Kazakhs $-77,7 \%$, rural population $58,2 \%$. Nearly $100 \%$ of representatives of all ethnic groups knew Russian. List of students of the Kazakh schools is generally monoethnic. School students of other ethnic origin chose Russian as study language at school.

In Aktobe, despite a high number of the Kazakh population, the choice of Russian for studying among a part of Kazakh students is rather high. This research of features of the distribution of bilingualism in the student's environment showed that students widely use the Kazakh-Russian bilingualism in different communicative situations, generally with ease carry out switching of a language code, i.e., are real bilinguals. All students found a certain extent of knowledge of Russian as the second; however, the level of their language competence was exclusively different and depended on many extralinguistic factors.

$\mathrm{N}$. Zhanpeisova claims that most of the population of Kazakhstan are bilinguals. However, the extent of knowledge of Russian as the second is not identical (Zhanpeisova, 2006). The scientist considers that in Kazakhstan was created the national type of bilingualism (the Kazakh-Russian bilingualism): knowledge of Russian is widespread among the title population of the republic. The scientist assumes that in the city and areas with motley ethnic structure exists a quite big stratification in the language relation. Often in communication with representatives of other nationalities Kazakhs should use Russian as an intermediate language that influences the expansion of its functioning sphere. Bilinguals are intermediaries between multilingual national groups. Most of Kazakhs are bilingual therefore switching to another language, as a rule, is peculiar to persons of the Kazakh nationality.

Analyzing a language situation in Kazakhstan, O. Altynbekova (2003) comes to a conclusion that in the Republic of Kazakhstan the language situation is formed, first of all, due to functioning of the Kazakh-Russian bilingualism (75\% of representatives of the title nation know Russian), in the second, Russian speaking (Russians, Belarusians, Ukrainians, Poles, Germans, Koreans, Greeks, Moldavians, a mordva, Chuvashs, etc.), the national-Kazakh-Russian bilingualism (Uzbeks, Uyghurs, Turks, Kurds, Azerbaijanians, Tajiks, Chechens, Kyrgyz, Tatars, the dungena, Bashkirs, etc.). It is important to notice that in percentage terms in this multilingualism of different ethnic groups, excepting Tajiks and Uzbeks, Russian dominates.

In this regard, exclusive relevance is acquired by necessity of a complex and comprehensive research of real functioning not only state language, but also Russian at the present stage of economic and political development of Kazakhstan, definition of population readiness to adapt to new state language policy, dependence of the linguistic environment from geographical, ethnic, demographic and other extralinguistic factors. On the basis of the analysis of new ethnolanguage processes and balance of language priorities, it is necessary to try to reconsider traditional 
concepts of language policy and a language situation which developed in recent years of the independence.

\section{Conclusion}

The efficiency of realization of language policy in the Republic of Kazakhstan within the State program of functioning and development of languages is impossible without understanding of a real linguistic situation in the country and the language planning based on this analysis in consideration of the actual role and socio-communicative functions of Russian in language space of Kazakhstan. A clear idea of a language situation peculiarity in the Republic and its dynamics under the influence of new language policy will allow making practical offers on the creation of such formula of tolerant interethnic interaction which will allow the peoples living in multiethnic Kazakhstan to keep the language rights and cultural orientations.

Sociopolitical realities of Kazakhstan as sovereign state demand new language policy which would have to meet needs of the multiethnic population of the country and consider features of a language, demographic and political situation. The characteristic of a language situation needs an interpretation of language processes by political scientists, sociologists, jurists and linguists as the need of development of effective public language policy assumes adequate assessment of a real language situation.

Today in Kazakhstan works the Concept of language policy directed to expansion of the functioning sphere of a state language and defines Russian as the main source of information and as the mode of communication. The existing model of languages functional development defined in the Concept also assumes the creation of an optimum language space of the state, in this connection, an accurate definition of a functional ratio of languages, at which the state language had to take the worthy place, is required. The goal gives to Kazakh language function of international communication language, demands adoption of the new legislation and accurate state programs of functioning and development of languages. The Concept also guarantees to Russian language preservation in full of those social functions which it possessed in the mid- 90 s years of the 20th century in already independent Kazakhstan. According to the Concept, interests of economic and scientific and technical development of the country define demand for knowledge and education received in Russian. Preservation of the functioning sphere of Russian is provided with the aspiration of Kazakhstan to integration processes, preservation of uniform cultural and educational space with the CIS countries.

\section{Bibliographic references}

ADAMSON, B. - FENG, A. 2014. Models for trilingual education in the People's Republic of China, Minority languages and multilingual education, Springer Netherlands, pp. 29-44.

AKHMETZHANOVA, Z. 2005. Comparative linguistics: Kazakh and Russian languages. Alma-Ata: Kazakh Ablai Khan University of International Relations and World Languages.

ALTYNBEKOVA, O. 2003. Bilingualism: Program of sociolinguistic research. Almaty: KRELS.

APPEL, R. - MUYSKEN, P. 2005. Bilingualism and Language Contact. London: MITPress.

BAZIYEV, A. - ISAEV, M. 1973. Language and nation. Moscow: Science.

DESHERIYEV, Y. - PROTCHENKO, I. 1972. Main aspects of research of bilingualism and multilingualism. Problems of bilingualism and multilingualism. Moscow: Science, pp. 26-42. 
GARCÍA, O. - WEI, L. 2015. Translanguaging, bilingualism and bilingual education. Handbook of bilingual education, pp. 223-240

HOFFMANN, C. 1991. Introduction to Bilingualism. N.Y.: Longman Group Ltd.

KHASANOV, B. 1989. National languages, bilingualism and multilingualism: searches and prospects. Alma-Ata: Kazakhstan.

KARLINSKY, A. 1990. Bases of the theory of interaction of languages. Alma-Ata: Gylym.

KHASANOV, B. - DESHERIYEV, Y. 1976. Language of international communication. Alma-Ata: Kazakhstan.

KOPYLENKO, M. - SAINA, S. 1982. Functioning of Russian in various layers of the Kazakh population. Alma-Ata: Science.

KURMANOVA, B. 2002. Sociolinguistic problems of functioning of a state language in the western region of the Republic of Kazakhstan. The abstract of the thesis on protection of the status of the doctor of philological sciences. Almaty: Al-Farabi Kazakh National University.

Language policy in Kazakhstan and a way of her realization: theses of a republican scientific and practical conference. 1990. Alma-Ata: Institute of linguistics.

LYUBIMOVA, N. 1991. Phonetic interference and communication in non-native language (pilot study on material of the Finnish-Russian bilingualism). The abstract of the thesis on protection of the status of the doctor of philological sciences. St. Petersburg: St. Petersburg State University Publishing House.

MARSCHARK, M. - KNOORS, H. - TANG, G. (eds.). 2014. Bilingualism and bilingual deaf education. USA: Oxford University Press.

MEHISTO, P. - GENESEE, F. 2015. Building Bilingual Education Systems. Cambridge University Press.

MIKHAYLOV, M. 1988. Bilingualism in the modern world: Education guidance. Cheboksary: Publishing House of the Chuvash State University of I. N. Ulyanov.

RAKHIMZHANOV, K. 2005. Language contacts and their reflection in regional, fiction (on material of works of writers of the Pavlodar Priirtyshje). The abstract of the thesis on protection of the status of the doctor of phylological sciences. Almaty: Al-Farabi Kazakh National University.

RAKISHEVA, B. 2003. Sociological analysis of language processes in the Republic of Kazakhstan, The abstract of the thesis on protection of the status of the doctor of philological sciences. Almaty: Al-Farabi Kazakh National University.

SHAYAKHMETOVA, A. 2002. Bilingualism in society and children's bilingualism. Messenger of KAZGU: Philology series, vol. 2, pp. 6-10.

SHCHERBA, L. 1958. Chosen works on linguistics and phonetics. Leningrad: Publishing house of the Leningrad University.

SULEYMENOVA, E. 2011. Language processes and policy. Almaty: Kazakh University Publishing House.

VAYNRAYKH, U. 1979. Language contacts: condition and problems of a research. Kyiv: High school.

XASANULI, B. 1992. Mother language is inherited from a parent (in Kazakh language role in the languages of the earth). Alma-Ata: the Writer

ZHANALINA, L. 1998. Functioning of Russian in the Republic of Kazakhstan. Almaty: Science.

ZHANPEISOVA, N. 2006. Representation of national spheres of concepts in a picture of the world of the Kazakh-Russian bilinguals. The abstract of the thesis on protection of the status of the doctor of philological sciences. Ufa: Publishing house of BashGU.

Words: 4962

Characters: 34717 (19,29 standard page) 
Prof. Tulebike Kulgildinova

Department of international communications

Kazakh Ablai khan University of international relations and world languages

200 Muratbayev str.

Almaty

Kazakhstan

aigzhum@mail.ru

Prof. Aigul Zhumabekova

Department of Oriental Languages and Translation Study

Abay Kazakh National Pedagogical University

25 Zhambyl Str.

Almaty

Kazakhstan

aigulzhumabekova@yahoo.com

Kuralay Shabdenova

Department of Kazakh language

Karaganda State Technical University

Stepnoy 4 str,8-65

Karaganda

Kazakhstan

adal310501@gmail.com

Laila Kuleimenova

Department of Kazakh language

Karaganda State Technical University

Stepnoy 4 str,8-65

Karaganda

Kazakhstan

layla_k70@mail.ru

Perizat Yelubayeva

Department of foreing languages for specific and academic purposes

Kazakh Ablai Khan University Of International Relations And World Languages 200 Muratbayev str.

Almaty

Kazakhstan

perizat_fmo@mail.ru 